\title{
SOBRE LA GENERALIDAD DE LAS LEYES: LIBORIO HIERRO Y FRANCISCO LAPORTA
}

\author{
José Juan Moreso \\ Universidad Pompeu Fabra
}

\begin{abstract}
The general law is opposed to any kind of individual command. The difference is a relative one [...] it is undoubtedly true that the execution of the any command leaves to the commanded person a certain kind of initiative.
\end{abstract}

NEUMANN (1986: 212)

Porque el Derecho no es, ni puede siquiera ser aunque se pretendiese [...] el texto de la ley y nada más, sino la ley con toda su textura de principios y de conceptos capaces de una vida propia, vida propia que no la audacia del juez y su pretensión protagonista impulsan, sino que exige rigurosamente el funcionalismo de la sociedad y la inserción en él de preceptos generales y estables.

GARCÍA DE ENTERRÍA (1981: 224)

\section{INTRODUCCIÓN}

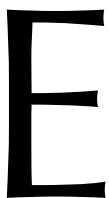

n el grupo de Filosofía del Derecho de la Universidad Autónoma de Madrid la preocupación por el lugar del Estado de derecho y, en particular, del imperio de la ley, en nuestros enfoques conceptuales acerca del derecho y la democracia ha ocupado y ocupa un lugar central. Y es que es un asunto crucial para nuestra concepción del derecho. Ello se debe, en gran medida, me parece, a la importancia del libro de Elías DíAz (1966), Estado de Derecho y sociedad democrática, tal vez el libro más importante en la cultura jurídico-política del tardofranquismo. Después vendría la seminal contribución de GARCÍA DE ENTERRÍA (1981) sobre la Constitución como norma jurídica, pero este es un libro para la transición democrática, para la nueva democracia constitucional española, que el anterior solo podía atisbar en medio de la larga noche de la dictadura ${ }^{1}$. No es esta la única razón, pero es relevante, por la que me alegra participar en este seminario que celebra la jubilación de Liborio HIERRO y de Francisco LAPORTA, dos personas de las que tantas cosas aprendí cuando me formaba en filosofía del derecho y que, con el transcurrir del

1 Para mí, y supongo que para los juristas de mi generación, ambas obras vienen juntas, las leímos con devoción durante los estudios de Derecho en la Facultad. De hecho, mi ejemplar del libro de Elías Díaz es

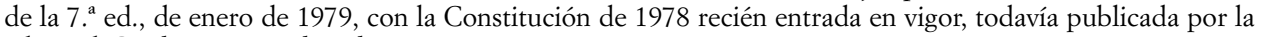
editorial Cuadernos para el Diálogo. 
tiempo, han devenido dos amigos entrañables. En esta Universidad, su casa, gracias a ellos y a los demás amigos del grupo, siempre me he sentido en casa.

He de referirme aquí a su noción de imperio de la ley². LAPORTA la convirtió hace ya algunos años en otra de estas contribuciones cruciales a la cultura jurídico-política del presente en LAPORTA (2007). Y ese punto es uno de los rasgos formales que siempre se atribuye a la idea de imperio de la ley, a la idea de rule of law, me refiero a la generalidad de las normas.

\section{EL CARÁCTER GENERAL Y ABSTRACTO DE LAS LEYES}

En una de las más perspicuas presentaciones de la idea de rule of law, Lon FULLER (1969: cap. II) estableció los requisitos que, para su concepción, constituyen la moralidad interna del derecho. Pues bien, la generalidad constituye un rasgo crucial de dicha concepción. Y se supone que la generalidad tiene dos dimensiones, una referida a los sujetos normativos, los destinatarios de las prescripciones, y otra referida a las acciones ordenadas, al contenido de las prescripciones. Así lo expone, por ejemplo, Riccardo GUASTINI (1993: 22):

En sentido estricto, se habla de «norma» para referirse a todo enunciado que expresa una regla de conducta, o más precisamente una regla de conducta general y/o abstracta. General: en el sentido de que los destinatarios de la norma no son un individuo singular, sino una clase de individuos. Abstracta: en el sentido de que la regla se aplica no a un supuesto de hecho singular, sino a una clase de supuestos de hecho.

Por tanto, las leyes son generales si se refieren a una clase universal de individuos, si no contienen - se añade a veces - ni nombres propios ni descripciones definidas (FulLER, 1969: 43, vid. también esta idea en HARE, 1953: 175-179). Y las leyes son abstractas si no se refieren a acciones individuales, como el atentado de las Torres Gemelas en Nueva York, sino a acciones genéricas, como las acciones terroristas (ALCHOURRÓN, BuLYGIN, 1971: cap. I).

Las leyes generales muestran, de este modo, un compromiso con dos valores que la rule of law quiere servir: el valor de la predictibilidad y el valor de la equidad. Al ser generales, podemos averiguar previamente a su aplicación si nuestras acciones podrán o no ser subsumidas en ellas y, si son aplicadas consistentemente, tratarán los casos iguales -iguales con el parámetro de la ley- de manera igual. Como LAPORTA muestra con gran agudeza (2007: cap. I) solo así las leyes respetan nuestra autonomía personal, la capacidad de dirigir nuestras vidas como modo de alcanzar aquellos fines que pretendemos.

\section{LAS LEYES Y LOS NOMBRES PROPIOS}

Sin embargo, ambas dimensiones de la generalidad de las leyes deben ser matizadas. Referida a los sujetos normativos es necesario establecer una considerable

2 Vid, p. ej., HiERro (1996; 2002) y LAPORTA (2007). 
cantidad de excepciones. Mientras es claramente exigible a las normas penales que tipifican los delitos y a las normas que establecen las obligaciones privadas contractuales, hay otras muchas leyes en donde esta exigencia no es tan razonable. Pensemos en la Ley de Presupuestos, mientras era rector en la Universidad Pompeu Fabra y durante los años previos a la crisis económica, el debate de los presupuestos y la presentación de enmiendas se convirtieron en la posibilidad de negociar determinadas partidas para intereses públicos diversos. Yo mismo procuré, con éxito en varias ocasiones, que se habilitaran partidas para subvencionar diversos aspectos de los centros de investigación vinculados con mi Universidad. Y, claro, aquí los nombres propios son necesarios, de hecho la Ley de Presupuestos está llena de nombres propios.

De hecho, merece la pena recordarlo aquí, fue la voluntad de Bismarck de no someter al Parlamento la aprobación de determinadas partidas económicas para sus empresas bélicas, la que condujo a la elaboración dogmática (obra de Paul LABAND, 1870, un jurista orgánico) de la distinción entre ley en sentido formal y ley en sentido material, dejando fuera de la competencia del Parlamento las leyes que solo lo son en sentido formal. Si no queremos regresar a esta «mendacidad intelectual, [...] sepulcro blanqueado, [...] orientación política criptoabsolutista, conforme a la cual la importancia de la Asamblea legislativa queda reducida a la nada», como la llamó Alf Ross (1929: 459), habrá que dejar fuera del requisito de generalidad las leyes que confieren poderes institucionales o que establecen obligaciones de gasto a la Administración y otras muchas. HIERRO (1996) es bien consciente de este fenómeno y lo describe con claridad y agudeza y lo mismo vale para LAPORTA (2007: 156, explícitamente contra la construcción de LABAND).

\section{TODAS LAS PRESCRIPCIONES SON ABSTRACTAS}

Un problema de naturaleza conceptual -y más grave, por tanto- presenta, no obstante, la idea de que las leyes deben ser abstractas, en el sentido de que deben regular comportamientos descritos mediante acciones genéricas y no mediante acciones individuales. Dicho en pocas palabras: todas las prescripciones regulan el comportamiento mediante la descripción de acciones genéricas, porque no pueden hacerlo de otro modo. Incluso en la orden más individual que podamos imaginar, por ejemplo la orden del sargento de cocina al soldado Ticio (y en este sentido la regla no es general dado que no es referida a una clase de individuos), «jlava los platos!», la acción ordenada es abstracta, y Ticio puede cumplirla de múltiples (de hecho de infinitas maneras): lavando primero los platos más grandes y después los más pequeños, o al revés, o ahora unos y después otros, etc. Todas las reglas prescriptivas son abstractas ${ }^{3}$.

Sin embargo, en la literatura de la rule of law, se suele insistir en este rasgo de las leyes, como si pudiera estar ausente de ellas. En uno de los loci classici, HAYEK (1973: 86) sostiene: «Las reglas [...] deben ser abstractas en el sentido de referidas a un número

\footnotetext{
3 El mismo argumento referido, sin embargo, a los enunciados de razones en ALCHOURRÓN (1996: 118).
} 
limitado de circunstancias relevantes y de ser aplicables al margen de las consecuencias particulares que parecen ahora seguirse de su aplicación». Ahora bien, ¿qué sentido tiene decir que las reglas deben ser abstractas si no pueden no serlo?

Otros autores parecen atisbar este rasgo de las prescripciones. En su análisis de la generalidad de las leyes, FULLER (1969: 48) afirma:

En los sistemas actuales de control y dirección de la conducta humana un fracaso completo a la hora de lograr algo como una regla general es raro. Alguna generalización está implícita incluso en el acto de comunicar un deseo singular. La orden a un perro, «dame la patita» exige algún poder de generalización tanto en el dueño como en el perro. Antes de cumplir la orden el perro ha de comprender qué rango de actos ligeramente diferentes serán aceptados como dar la patita.

Pero entre los clásicos de la rule of law tal vez fue Franz Neumann (1986: 212) ${ }^{4} \mathrm{el}$ que lo vio con mayor claridad:

La ley general se opone a cualquier tipo de orden individual. La diferencia es relativa. Es cierto que todas las órdenes de una autoridad superior a un órgano inferior de realizar cierto acto son, en relación con el cumplimiento de la orden, siempre generales y abstractas [...]. Es indiscutiblemente verdad que el cumplimiento de cualquier orden deja a la persona a la que va dirigida un cierto margen de iniciativa. Desde este punto de vista, la orden individual puede ser contemplada como una orden general.

También Guastini (en Guastini, 2010: 15-17) distingue ahora dos sentidos del carácter abstracto de las leyes. Y aunque en un primer sentido sigue sosteniendo que «una prescripción no es abstracta cuando se refiere a un supuesto de hecho concreto y singular (pasado o futuro, poco importa), y no a una clase de supuestos de hecho», en un segundo sentido una ley es abstracta cuando no es retroactiva, «una prescripción no es abstracta cuando se refiere a un supuesto de hecho - un supuesto de hecho singular o una clase de supuestos de hecho, poco importa-pasados, ya verificados y por ello previamente identificados, o al menos, identificables».

Aquí parece que GUASTINI intuye, aunque no lo dice, que solo podemos referirnos a acciones individuales pasadas, claro también en el supuesto de hecho de la norma, pero no podemos prescribir acciones individuales, para el futuro, por razones lógicas.

También LAPORTA (2007: 86-87) atisba el problema cuando escribe: «Naturalmente, las normas jurídicas tienen en general como contenido actos genéricos, pues de lo contrario sería imposible para un legislador regular la vida en sociedad recurriendo a la prescripción de actos individuales hipotéticos». Pero más adelante (LAPORTA, 2007: 89) sostiene que las normas pueden ser generales acerca del contenido y no acerca de los destinatarios y al revés. Y afirma que una norma general respecto a los destinatarios pero no acerca del contenido podría ser aquella que ordena «a todos los vecinos de una localidad (norma general respecto de los destinatarios) que vayan a donar sangre a un hospital un día determinado y solo ese día, como consecuencia de que

${ }^{4}$ El libro de NEUmann es su tesis doctoral defendida en 1936, dirigida por Harold LASKI, en la London School of Economics, donde se había refugiado huyendo del nazismo. Una obra no publicada hasta 1986, NEUMANN es más conocido por su Behemoth (1944), pero tal vez sea el mayor jurista de la Escuela de Frankfurt, desafortunadamente muerto en accidente en 1954. 
se ha producido una catástrofe natural en la localidad». Sin darse cuenta, al parecer, de que esta orden es genérica, abstracta, acerca del contenido. Los vecinos pueden ir a donar sangre por la mañana o por la tarde, en bicicleta o en coche o paseando, vestidos de un modo o de otro, etc. Y más aún, parece que también cumplen con la norma los vecinos que donan sangre sabiendo que están enfermos de hepatitis o están infectados con el virus de inmunodeficiencia adquirida.

Hay un modo de mantener la distinción, sin embargo, entre normas generales o abstractas y normas particulares ${ }^{5}$. Se trata (siguiendo a VON WRIGHT, 1963: 79-81) de no referir la distinción al contenido de las normas, que — como hemos visto- siempre es general, sino a la ocasión de las normas, al lapso espacio-temporal en que deben ser cumplidas. Entonces, las normas son abstractas, respecto a la ocasión sino establecen lapso espacio-temporal ninguno, si establecen alguno son particulares. VON WRIGHT (1963: 79) lo dice así:

Los contenidos de las prescripciones que son nuestro objeto de estudio son determinados actos u omisiones genéricos. Aquellos contenidos normativos son ordenados o permitidos a los sujetos normativos por las autoridades normativas para que los lleven a cabo mediante actos u omisiones individuales en determinadas ocasiones.

La ocasión se refiere a una localización, un lugar o un periodo de tiempo. Cuando la prescripción en cuestión va referida a una ocasión específica o a un número finito de ocasiones específicas, entonces es particular. Cuando la prescripción va referida a un número ilimitado de ocasiones entonces es eneral $^{6}$.

\section{LA APLICACIÓN DE LAS LEYES}

Y ahora es cuando nos enfrentamos con el problema de la aplicación de estas prescripciones generales. La concepción de las leyes como reglas generales supone que la generalización que contiene determina su aplicación. Los órganos jurisdiccionales deben decidir los casos individuales a la vista de estas generalizaciones. Estas generalizaciones aparecen, como dice - en el mejor de los libros contemporáneos al respecto- Frederick SCHAUER (1991: 23-24) «atrincheradas», opacas a la razón que las justifica. Lo que representa (SCHAUER, 1991: 31-34) que habrá casos incluidos en la regla que conforme a la razón que justifica tener la regla no deberían estar incluidos. Creo que es más que razonable —en el ejemplo de LAPORTA— que quien deba examinar el cumplimiento de dicha norma considere no incluidos en ella a los que con su sangre pueden dañar a otros, que no deben donarla, y también a los que, pudiendo donarla, pueden ser autorizados a no hacerlo: las mujeres embarazadas, los enfermos, los que tienen la tensión muy baja, los que se hallan fuera de la localidad ese día por razones de trabajo, tal vez también los testigos de Jehová por respeto a

5 Percatarme de ello lo debo a sendas conversaciones con Ricardo CARACCIOLO en donde amablemente me presionó en esta dirección, en Barcelona y en Ciudad de México en el otoño de 2016.

${ }^{6}$ LAPORTA (2007: 85-94) sigue la caracterización de los elementos de las prescripciones de vON WRIGHT. Sin embargo, y a pesar de sus relevantes consideraciones sobre los aspectos temporales de la ocasión (referidos a la retroactividad de las prescripciones), no pone en relación el carácter abstracto de las normas con la ocasión. 
sus confesiones religiosas ${ }^{7}$. Ello puede alcanzarse si quien aplica la norma, si la jurisdicción, está inspirada no solo por las reglas generales, sino también, como señala GARCÍA DE ENTERRÍA (1981: 224), por los principios y los conceptos que subyacen a ella.

Como nos recuerda Jeremy WALDRON (2011: 82), matizando su anterior posición, ARIsTÓTELES, en un célebre pasaje de la Ética a Nicómaco (1984: 1137b: 83) nos dice que hay dimensiones de las acciones humanas que no pueden ser capturadas por reglas universales y para tratarlas debemos usar instrumentos no rígidos, y las reglas generales son rígidas, debemos usar reglas flexibles (reglas con defeaters) «como la regla de plomo de los arquitectos lesbios, que se adapta a la forma de la piedra y no es rígida».

\section{REFERENCIAS BIBLIOGRÁFICAS}

AlChourrón, C. E., 1996: «Para una lógica de las razones prima facie», Análisis Filosófico, 16: $113-124$.

AlChourrón, C. E., y BulYgin, E., 1971: Normative Systems, New York-Wien: Springer.

ARISTÓTELES, 1984: Ética a Nicómaco, trad . de M. Araújo y J. MARíAs, Madrid: CEC.

DíAz, E., 1966: Estado de Derecho y sociedad democrática, Madrid: EDICUSA.

FulLer, L. L., 1969: The Morality of Law, New Haven: Yale University Press.

GARCía de ENTERRíA, E., 1981: La Constitución como norma y el Tribunal Constitucional, Madrid: Civitas.

GuASTINI, R., 1993: Le fonti del diritto e l'interpretazione, Milano: Giuffrè.

- 2010: Le fonti del diritto: Fondamenti teorici, Milano: Giuffrè.

HARE, R. M., 1953: The Language of Morals, Oxford: Oxford University Press.

HaYeK, F. A., 1973: Law, Legislation and Liberty. Vol. I: Rules and Order, Chicago: Chicago University Press.

HierRo, L., 1996: «El imperio de la ley y la crisis de la ley», Doxa, 19: 287-308.

— 2002: «¿Por qué ser positivista?», Doxa, 25: 263-302.

LABAND, P., 1870: Das Budgetrecht nach den Bestimmungen der preußischen Verfassungsurkunde (Berlin: Guttentag), trad. de J. ZAмiт, Derecho presupuestario, Madrid: Ministerio de Hacienda, 1979.

LAPORTA, F. J., 2007: El imperio de la ley. Una vision actual, Madrid: Trotta.

Moreso, J. J., 2016: «Con la plomada de Lesbos. Celano sobre Rule of Law y particularismo», manuscrito, en academia.edu.

Neumann, F., 1944: Behemoth: The Structure and Practice of National Socialism 1933-1944, expanded edition, New York: Harper \& Row.

- 1986: The Rule of Law. Political Theory and the Legal System in Modern Society, Leamington Spa: Berg.

Ross, A., 1929: Theorie der Rechtsquellen. Ein Beitrag zur Theorie des positiven Rechts auf Grundlage dogmengeschichtlicher Untersuchungen, Leipzig: Franz Deuticke, trad. de J. L.

7 Como he señalado en otro lugar (MORESO, 2016), precisamos de una teoría adecuada de los defeaters jurídicos, de su naturaleza, de cuándo, cómo y por quién se activan, y de su taxonomía. Es un punto que merece una indagación autónoma y que no puedo adelantar aquí. 
Muñoz de Baena Simón, A. de Prada García, y P. López Pietsch, Teoría de las fuentes del derecho, Madrid: CEPC, 1999.

Schauer, F., 1991: Playing by the Rules, Oxford: Oxford University Press.

Von Wright, G. H., 1963: Norm and Action. A Logical Enquiry, London: Routledge \& Kegan Paul.

Waldron, J., 2011: «Vagueness and the Guidance of Action», en A. Marmor y S. SOAmES (eds.), Philosophical Foundations of Language in the Law, Oxford: Oxford University Press, 58-82. 